\title{
Lifetime impact of cash transfer on fertility
}

\author{
Young-Il Albert Kim ${ }^{1}$
}

\begin{abstract}
In most OECD countries, fertility level is below the natural generation replacement level, and many OECD countries implement pro-natal policies, including direct cash transfer schemes. However, evaluations of the long-run impact of such policies are surprisingly rare. We investigate whether the cash transfer increases completed fertility, exploiting a quasi-experiment from a pro-natal cash transfer called Allowance for Newborn Children (ANC). We first devise a measure of ANC impact for different birth cohorts, because the policy lasted for a decade and affected cohorts with different intensities at different ages. The results show that ANC impact on fertility has little permanent component.
\end{abstract}

Keywords: fertility, child subsidies, birth subsidies.

\section{Résumé}

Dans la plupart des pays de l'OCDE, le taux de fertilité est inférieur au niveau de renouvellement naturel des générations; plusieurs pays de l'OCDE mettent en place des politiques natalistes incluant des modèles de transferts pécuniaires. Cependant, des évaluations sur l'impact à long terme de ces politiques sont étrangement rares. Dans cet article, nous examinons si le transfert pécuniaire augmente la descendance finale, exploitant la quasi-expérience du transfert pécuniaire prénatal appelé l'allocation à la naissance ou « bébé bonus ». Nous imaginons d'abord une mesure de l'impact de cette politique pour différentes cohortes de naissance parce que la politique a duré une décennie et a touché des cohortes à des degrés différents et à des âges différents. Les résultats indiquent que l'impact de l'allocation à la naissance sur la fertilité n'est pas vraiment permanent.

Mots-clés : fertilité, allocation pour enfant, allocation de naissances.

\section{Introduction}

Fertility levels of most OECD countries started to fall rapidly in the 1970s, and their fertility levels were below replacement level by 1983 (see Figure 1). By 2002, total fertility levels of all OECD countries except Mexico and Turkey were below replacement level (OECD 2005). Assuming no external migration, the population level will decrease in those countries, adversely affecting their population structure. Decreasing population lowers the growth of real GDP, per capita GDP, and domestic savings, and changing the population structure creates pressure on the government budget, as a smaller number of the working population will have to support greater numbers of pensioners. Most OECD countries have tried to instigate birth by policy instruments, including family cash benefits, childcare support programs, increased duration of maternity and parental leave, and general social protection system. Cash transfer is one of the most popular pro-natal policies. As of 1998, almost eighteen OECD countries were spending more than one per cent of total GDP on family cash benefits to instigate birth, including Australia, France, and the United Kingdom (Sleebos 2003).

1. Department of Economics, Sogang University in Seoul, South Korea. Email: yakim@sogang.ac.kr. 


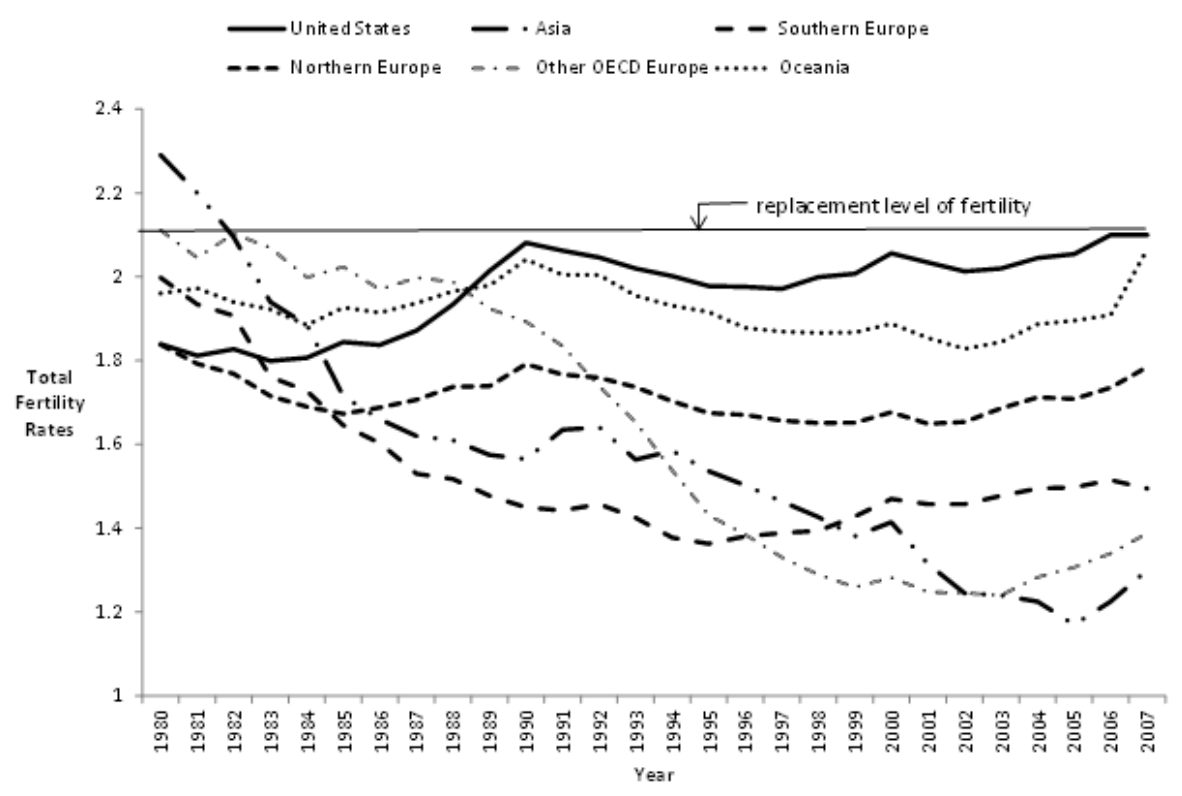

Figure 1. Total fertility rates of OECD countries from 1980 to 2007.

Source: OECD Statistics (http://stats.oecd.org/Index.aspx).

Note: Asia includes Japan and South Korea. Southern Europe includes France, Italy, Portugal and Spain. Northern Europe includes Austria, Belgium, Denmark, Finland, Germany, Iceland, Ireland, the Netherlands, Norway, Sweden, Switzerland and the United Kingdom. Other OECD Europe includes Czech Republic, Estonia, Hungary, Poland, Slovak Republic and Slovenia. Oceania includes Australia and New Zealand.

Buttner and Lutz (1990) and Hoem (1990) find that a set of pro-natal policies in East Germany and Sweden-mainly aimed at reducing child-rearing costs-were effective in increasing fertility. Recent evidence from France and Israel indicates that such policies are also effective in increasing fertility (Salanie and Laroque 2005; Cohen et al. 2007). Zhang et al. (1994) show that all of the fiscal incentives for giving births in Canada, such as personal tax exemption for children, child tax credit, family allowances, and maternity leave benefits, all have statistically significant and positive effects on fertility, using vital statistics from 1921 to $1988 .^{2}$ In Canada, the provincial government of Quebec implemented a universal cash transfer scheme called the Allowance for Newborn Children (ANC) from May 1988 to September 1997 to all legal residents of Quebec. ${ }^{3}$ Figure 2 shows total fertility rates for Quebec and Canada from 1970 to 2007, and it seems that the fertility gap between Quebec and Canada quickly closes during the ANC. Milligan (2005) uses household-level census data, and finds that the implied percentage increase in probability of having a child is approximately 12 per cent, as summarized in Table $1 .{ }^{4}$ However, evaluation of the long-run policy impact is surprisingly rare.

2. A personal tax exemption giving a tax deduction to dependents was first introduced in 1918 in Canada. In 1945, the family allowance benefit to all families with dependent children was introduced, and maternity leave benefits were available starting in 1971 as part of the Unemployment Insurance Program. Later, a child tax credit was introduced in 1977.

3. Duclos et al. (2001) find a positive effect of the ANC on fertility, using data obtained only from vital statistics.

4. See Table 1 for a summary of past studies. Buttner and Luz (1990) study the strong pro-natal policy implemented in East Germany in 1972. They show that age-specific fertility levels increased in response to the policy. Hoem (1990) shows that increasing financial incentive to birth increased fertility rates in Sweden. Salanie and Laroque (2005) use a microsimulation model and individual-level data to show that financial incentives have a significant impact on increasing fertility in France. Cohen et al. use child subsidy-level 


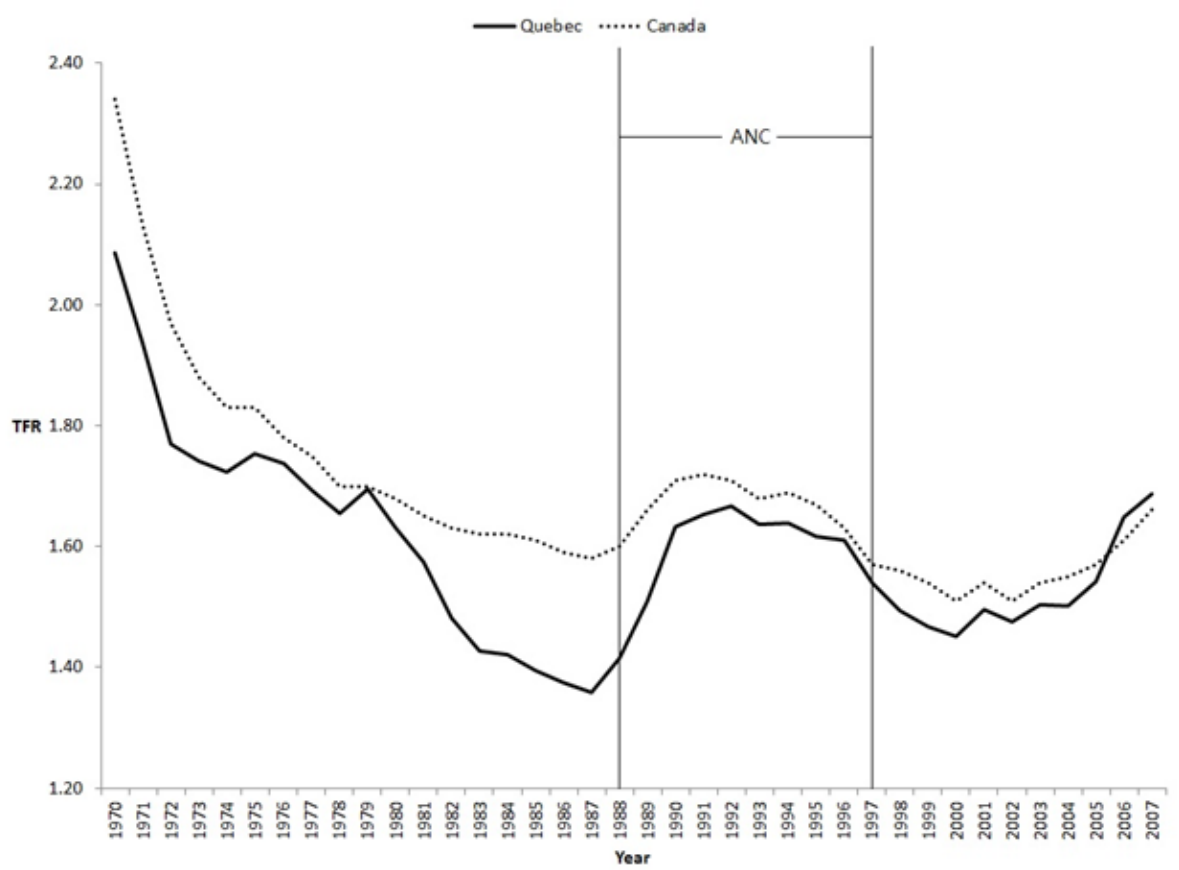

Figure 2. Total fertility rates of Quebec and Canada from 1970 to 2007.

Source: Cansim data table 5 for 91-209-X for Canada. Institute de la statistique Quebec for Quebec (http://www.stat.gouv.qc.ca/donstat/societe/demographie/naisn_deces/ naissance/402.htm).

Table 1: Summary of short-term policy evaluation studies.

France (Salanie 2005)

\begin{tabular}{ccclc}
\hline \multicolumn{2}{l}{ Estimated impact on fertility by parity } & \multicolumn{1}{c}{ Program description } & Data used \\
\hline 1st & 2nd & 3rd & - Size: $\sim 0.8 \%$ of GDP & French Labor \\
$2.20 \%$ & $6.70 \%$ & $9.00 \%$ & 1) Unconditional transfer & Force Survey \\
(up 1.1\%) & (up 2.0\%) & (up 1.8\%) & 2) Income-based transfer & (1997-1999) \\
& & & 3) Employment-based transfer & \\
& & & (Increasing in parity of birth) &
\end{tabular}

Israel (Cohen, Dehejia, and Romanov 2008)

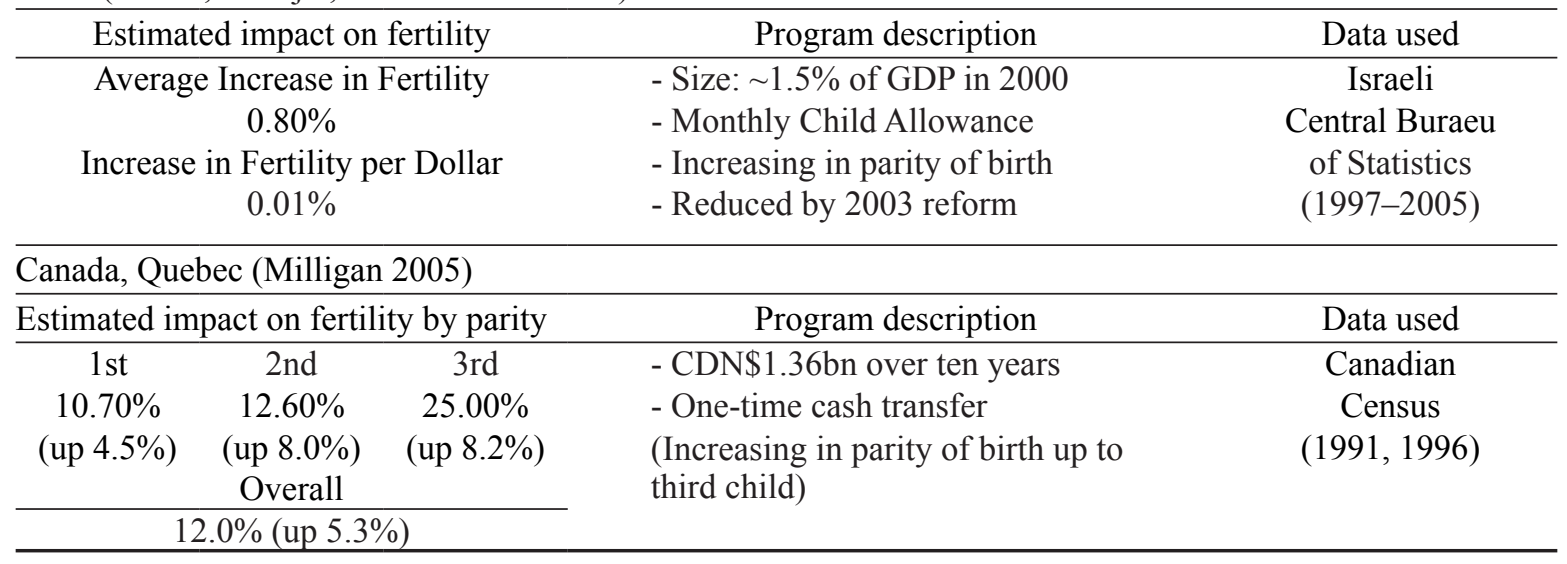

variation in June 2003 in Israel, using household-level data from 1999 to 2005 to show that reduction in child benefit has a significant impact on fertility decisions of Israeli households. Milligan uses Canadian Household Census data to show that the ANC had a significant impact on fertility. 
In this paper, we first devise a measure of policy impact on different birth cohorts, because the ANC lasted for a decade and each birth-year cohort of women was affected by the policy at different ages. Then we estimate the effect of the ANC on completed fertility level, the measure of lifetime fertility across time for each given cohort. We exploit the quasi-experimental nature of the universal cash transfer program, which lasted for a decade in only a part of the country, to investigate if the policy has a statistically significant impact on completed fertility. The results indicate that the ANC had little impact on increasing completed fertility of Canada.

\section{Empirical strategy}

Before we run our main analysis, we first replicate Milligan (2005) but we add age group as a dummy variable. The standard difference-in-differences method is used for the analysis of agespecific impact of the ANC, to verify that the policy impact varies by age group. If different age groups are affected differently by the ANC, some of the age-specific impact variation may be due to the shift in birth timing, and the long-run ANC impact may only be estimated by using completed fertility level. The dependent variable is whether the household had at least one child during the five-year census window. The linear probability method is used for the analysis. The equation to be estimated takes the following form:

$$
\begin{aligned}
\text { Had_a_child } & =\beta_{0}+\beta_{1} \text { Quebec }_{\mathrm{ij}}+\beta_{2} 1996 \text { dummy }_{\mathrm{it}} \\
& +\Sigma_{\mathrm{k}} \gamma_{\mathrm{k}} \text { Quebec }_{\mathrm{ij}} \times 1996 \text { dummy }_{\mathrm{it}} \times \text { Age_group_dummy } \\
\mathrm{ik} & +\sum_{\mathrm{m}} \delta_{\mathrm{m}} X_{\mathrm{ijtm}}+e_{\mathrm{ijt}},
\end{aligned}
$$

where $i$ indexes individuals, $j$ indexes provinces, $t$ indexes time, $k$ indexes age groups, and $m$ indexes individual traits. We used all the individual traits used by Milligan (2005). Predictor variables include demographic characteristics including: number of children born before the census window in each household; ages of the male members of each household as they were reported, as one of four age groups, 15-24, 25-34, 35-44 and 45+; marital status of the heads of each household; and immigrant status. We also include the socioeconomic variables, such as mother tongue and terminal level of schooling of the male and female spouse of each household, as well as an urban dummy variable that shows if the household was located in a census metropolitan area (CMA, which was formed by one or more adjacent municipalities centered on an urban area of at least 100,000 people). We also include a set of variables related to household income, including household income before social transfers, total of all household wages, household self-employed income, and household investment income. ${ }^{5}$ The ages of the female members of each household were reclassified into three groups-15-24, 25-34 and 35+-in making age-group dummy variables; $44+$ groups had little fertility; hence, the interpretation of the

5. The standard difference-in-difference method estimates how the quasi-experiment, ANC in this case, affects fertility probability by including a set of dummy variables specifying time period, location and their interaction term. Then, the constant $\beta_{0}$ measures the baseline average fertility probability for the non-Quebec 1991 Census window, while the coefficient for Quebec and 1996 Census window dummy variables estimate Quebec province-specific and 1996 census year-specific variations from the baseline. The coefficient of interest, the interaction term between Quebec and 1996 census window, then measures the effect of being in Quebec during the 1996 Census widow, or the treatment of the ANC, on fertility probability. 
Kim: Lifetime impact of cash transfer on fertility

key coefficient using this age group would be meaningless. The coefficient $\gamma_{k}$ represents ANC impact on probability of childbirth of age group $k$; hence, $\gamma_{k}$ would be greater than zero. If $\gamma_{\mathrm{k}}>\gamma_{\mathrm{k}^{\prime}}$, it indicates that the age group $k$ is more sensitive to the ANC than age group $k^{\prime}$. Idiosyncratic sensitivity, represented by different $\gamma_{k}$ for each age group, implies that the impact of policy differs by age group, and a measure of ANC impact should incorporate the varying age at which each cohort is exposed to the policy.

We devise a measure of the ANC on fertility for different cohorts using an age-specific fertility level variable called age-adjusted ANC exposure, and first run linear regression analysis to estimate the permanent impact of ANC on fertility:

$$
\begin{aligned}
& \text { Completed_fertility }{ }_{t}^{\text {Quebec }}=\beta_{0}+\beta_{1} \text { Age_adjusted_ANC_exposure }{ }_{t} \\
& \quad+\beta_{2} \text { Completed_fertility }_{t}^{\text {Rest_of_Canada }}+\beta_{3} \text { Cohort_year }{ }_{t}+\beta_{4} \text { Cohort_year }_{t}^{2}+e_{t},
\end{aligned}
$$

where $t$ indexes birth cohort. We included age-adjusted ANC exposure, completed fertility of rest of Canada, and the cohort year as independent variables. Any time-varying trend in the completed fertility level common to all Canada would be captured by completed fertility of rest of Canada. Cohort year and its quadratic term would capture other time- and provincial-varying factors that affect completed fertility in this model. The key coefficient is $\beta_{1}$. The coefficient represents impact of the ANC on completed fertility; hence, it would be greater than zero and significant if ANC has statistically significant impact on completed fertility level.

We test if the results are robust to the use of an alternative measure of ANC impact by replacing the measure of ANC impact from age-adjusted ANC exposure to the number of childbearing years that each cohort spent under ANC. Age 15-44 is considered childbearing, as the age group is typically used to estimate total fertility rate.

Then we use the difference-in-differences method in equation (3) to estimate the impact of the ANC on completed fertility level, treating completed fertility level of both Quebec and the rest of Canada as dependent variables:

$$
\begin{aligned}
\text { Completed_fertility }_{j t}= & \beta_{0}+\beta_{1} \text { Age_adjusted_ANC_exposure }{ }_{j t} \\
& +\beta_{2} \text { Quebec }_{j}+\beta_{3} \text { Cohort_year }_{t}+\beta_{4} \text { Cohort_year }_{t}^{2} \\
& +\beta_{5} \text { Quebec }_{j} \times \text { Cohort_year }_{t}+\beta_{6} \text { Quebec }_{j} \times \text { Cohort_year }_{t}{ }^{2}+e_{\mathrm{jt}} \text {, }
\end{aligned}
$$

where $j$ indexes provinces and $t$ indexes time. In this model, we aggregate data from Quebec and the rest of Canada, treating age-adjusted ANC exposure of rest of Canada as zero, to test if the results are still robust. The Quebec dummy variable coefficient controls any time-invariant Quebec-specific trend and time-trend dummy variable coefficients of the cohort year, and its quadratic term controls any region-invariant time trend. The interaction term coefficient $\beta_{5}$ captures the Quebec-specific time trend. The coefficient of interest is $\beta_{1}$, the measure of impact of ANC exposure on completed fertility. Again, if there is statistically significant impact of ANC on completed fertility level, the coefficient would be positive and significant. 
Table 2. Benefit payments under the allowance for newborn children.

\begin{tabular}{|c|c|c|c|}
\hline Period & First child & Second child & Third or higher child \\
\hline $\begin{array}{l}\text { May } 1988 \text { to } \\
\text { April } 1989\end{array}$ & $\mathrm{C} \$ 500$ at birth & $\mathrm{C} \$ 500$ at birth & $\begin{array}{c}8 \text { quarterly payments of } \\
\mathrm{C} \$ 375=\mathrm{C} \$ 3,000\end{array}$ \\
\hline $\begin{array}{l}\text { May } 1989 \text { to } \\
\text { April } 1990\end{array}$ & $\mathrm{C} \$ 500$ at birth & $\begin{array}{l}C \$ 500 \text { at birth, } \\
C \$ 500 \text { on } 1 \text { st birthday }\end{array}$ & $\begin{array}{l}12 \text { quarterly payments of } \\
\mathrm{C} \$ 375=\mathrm{C} \$ 4,500\end{array}$ \\
\hline $\begin{array}{l}\text { May } 1990 \text { to } \\
\text { April } 1991\end{array}$ & $\mathrm{C} \$ 500$ at birth & $\begin{array}{l}\mathrm{C} \$ 500 \text { at birth, } \\
\mathrm{C} \$ 500 \text { on } 1 \text { st birthday }\end{array}$ & $\begin{array}{l}16 \text { quarterly payments of } \\
\mathrm{C} \$ 375=\mathrm{C} \$ 6,000\end{array}$ \\
\hline $\begin{array}{l}\text { May } 1991 \text { to } \\
\text { April } 1992\end{array}$ & $\mathrm{C} \$ 500$ at birth & $\begin{array}{l}\text { C\$500 at birth, } \\
\text { C } \$ 500 \text { on } 1 \text { st birthday }\end{array}$ & $\begin{array}{l}20 \text { quarterly payments of } \\
\mathrm{C} \$ 375=\mathrm{C} \$ 7,500\end{array}$ \\
\hline $\begin{array}{l}\text { May } 1992 \text { to } \\
\text { September } 1997\end{array}$ & $\mathrm{C} \$ 500$ at birth & $\begin{array}{l}C \$ 500 \text { at birth, } \\
C \$ 500 \text { on } 1 \text { st birthday }\end{array}$ & $\begin{array}{c}20 \text { quarterly payments of } \\
\mathrm{C} \$ 400=\mathrm{C} \$ 8,000\end{array}$ \\
\hline
\end{tabular}

\section{Data}

Before and during the ANC, the provincial government of Quebec and the federal government already had various policy measures related to childrearing. ${ }^{6}$ In May 1988, the provincial government of Quebec enacted a universal cash transfer system, called the ANC, for all legal residents of the province. A household with a newborn baby received $\mathrm{C} \$ 500$ for the first and the second child, and $\mathrm{C} \$ 3,000$ for the third or higher parity child in cash. The amount gradually increased to $\mathrm{C} \$ 500$ for the first child, $\mathrm{C} \$ 1,000$ for the second child, and $\mathrm{C} \$ 8,000$ for the third or higher parity child—in cashby May 1992 (see Table 2). The program lasted for a decade, until May 1997, when it was replaced by other programs. The subsidy amount seems quite trivial to have a significant impact on fertility, at least for the first two years; hence, the full impact of the ANC may have started in the 1990s. ${ }^{7}$ We therefore consider the partially treated 1991 Census window to be the control when the impact of the ANC was minimal (see Figure 3).

For age-specific impact analysis in equation (1), we selected data from the 1991 and 1996 Canadian Census Public Use Microdata Files on Families to control for the individual household-level traits such as income, education level, language, immigration status, and age groups. The 1991 and 1996 census files reported 345,351 families and 342,231 families, respectively. ${ }^{8}$ We compared per-female age group probability of fertility of Quebec households relative to rest of Canada for the partially affected Census window (1991) versus the completely affected Census window (1996), to test

6. To name a few, various provincial governments provided basic non-taxable family allowances, young children allowances, personal income tax reduction/sales tax credits for lower-income families, and tax credits for children. The federal government of Canada provided taxable family allowances, refundable tax credits per child, credit sales tax per child, and a supplement for children under 7 up to 1992, as well as a child tax benefit program from 1993.

7. In May 1997, the ANC was replaced by the Quebec Family Allowance (QFA), which benefitted families with a family income of less than C $\$ 20,291$. The QFA is non-taxable and is paid to families each time they have a child; the stipend amount depends upon the family size and income. Low-income households have gained from these reforms, while the transfer was decreased for other sets of households (Baril et al. 2000). In addition, the Canada Child Tax Benefit (CCTB) and the National Child Benefit Supplement (NCBS) replaced the old Child Tax Benefit as part of the implementation of the National Child Benefit Program (NCB) at the federal level in 1998. The CCTB and NCBS subsidized births to low-income families at the federal level.

8. We excluded households that moved across provinces in the past 5 years, in order to remove samples whose place of childbirth could not be allocated clearly. People who were not legal residents of Canada were not eligible for the ANC, so they were excluded. Households that could not account for the number of children were removed as well. 
Kim: Lifetime impact of cash transfer on fertility

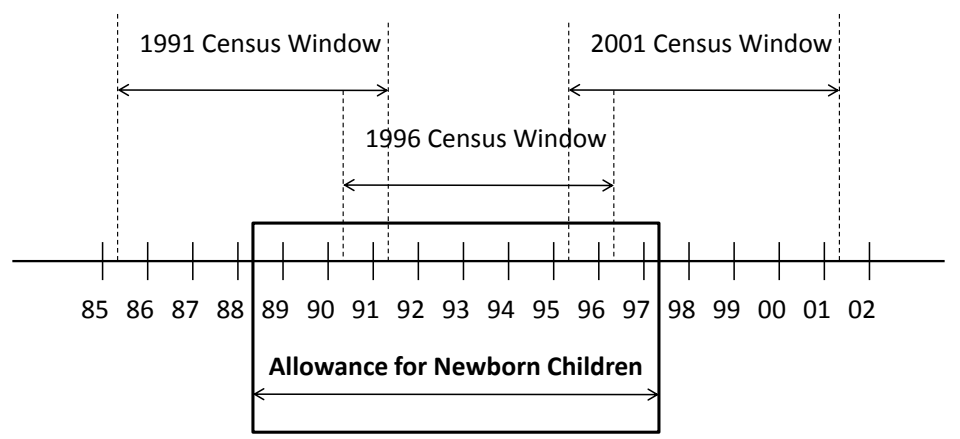

Figure 3. Census and ANC timing.

if the subsidy amount was substantial enough to significantly affect fertilities of households likely to be facing the terminal period in the lifetime birth cycle. ${ }^{9}$

The temporal shift in birth timing to earlier rather than later for households in Quebec may have been moderately alleviated by increasing the subsidy amount over the years. However, the subsidy amount was quite modest until in May 1992; hence, even if the timeline was revealed more than 40 weeks previous to any changes, the shift would have been minimal. As well, any temporal shift is more likely to produce children earlier than later, as households are still uncertain about the perpetuity of the policy. In order to address this issue, we analyze if the sizable part of the impact found by other studies of the ANC on fertility is due to the temporal shift in births.

We used completed fertility level of Quebec and of the rest of Canada and the 1934 to 1962 cohorts to analyze the effect of the ANC on completed fertility level, as in equation (2). However, measuring exposure to ANC per birth cohort is not straightforward. Fertility rate varies by age; hence, each cohort is affected differently by the ANC. Age-specific fertility measures how many children are born per 1,000 women in the age group on average. We created a measure of ANC exposure, called age-adjusted ANC exposure by incorporating the age-specific fertility rate for Quebec. The measure uses the age of each cohort during the decade at which the ANC was implemented, and estimates how many children are born on average per 1,000 women per cohort when they were under the influence of the ANC.

Age-adjusted exposure to ANC was estimated as follows. First, for each cohort, the age at which they were under the influence of the ANC was calculated; that is, the age of each cohort between 1988 and 1997. Then, the age-specific fertility of Quebec was summed up by the age at which each cohort was under the influence of the ANC. For example, for the 1944 birth cohort, as they were under the influence of the ANC between 44 and 53, we summed up the age-specific fertility level from 44 to 53. ANC impact, weighted by age-specific fertility level, is only 5.22 average births per 1,000 women for the 1944 cohort. ${ }^{10}$ Figure 4 shows completed fertility levels for Quebec and for the rest of Canada, along with age-adjusted exposure to ANC for the birth cohorts 1934 to 1962. Between 1988 and 1997, the ANC policy window, the 1944 birth cohort was aged between 44 and 53

9. Milligan (2005) also used the 1991 Census as a partially affected group and the 1996 Census as a completely affected group. Milligan only used females up to the age of 34 , as the focus of the study was to identify subsidy impact on fertility by family structure, and anyone older than 34 may have had older children who already left the household. As our focus is the triple-interaction with female age, we did not discard the female age group.

10. The 1944 birth cohort was under the influence of the ANC, with on average 5.22 children born out of 1,000 women of the age group, the total average number of children born between the ages 44 and 53 in Quebec. Likewise, the 1963 birth cohort was between 25 and 34 under the ANC and on average the total number of children born in the age range was 859 per 1,000 women. 


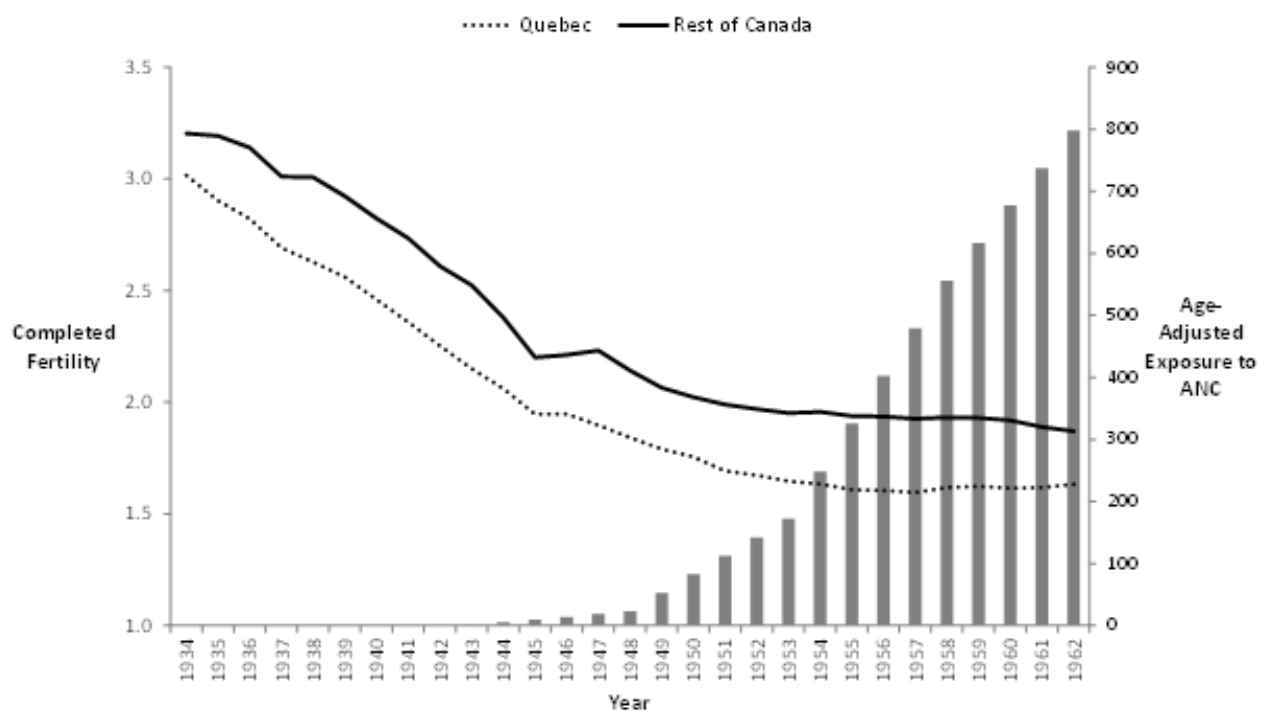

Figure 4. Age-adjusted exposure to ANC per cohort and completed fertility levels for Quebec and the rest of Canada by birth year (1944-1965).

Source: Statistics Canada data table 91-209X for completed fertility of Canada (http://www.statcan.gc.ca/pub/91-209-x/2011001/article/11513/figures/desc/ desc05-eng.htm), Institut de la Statistique Quebec for completed fertility of Quebec, CANSIM database Table 051-0001 and Canada Yearbook for population of Canada and Quebec from 1949 to 2006, for every five years. Completed fertility levels of 1963-1978 cohorts were also available, but they were projections; hence, we only used real data up to the 1962 birth cohort.

Notes: Age-adjusted exposure to ANC was estimated by summing the average annual age-specific fertility rate for Quebec from 2000-2005 (CANSIM database Table 102$4505)$ for the age at which each cohort was affected by ANC. Completed fertility for rest of Canada was estimated by subtracting population-weighted completed fertility rate for Quebec from completed fertility rate for Canada per cohort.

(see Figure 4). Once weighted by the age-specific fertility level, the 1944 cohort was the first cohort whose fertility level was significantly affected by the ANC. Age-adjusted exposure to ANC gradually increases until the 1962 cohort, which was aged between 24 and 33 when the ANC was present, at 798 average births per 1,000 women. Between the 1934 and 1963 cohorts, the decade-long ANC progressively affects age-adjusted exposure to ANC.

\section{Results and discussions}

Birth subsidies may only cause a temporal shift in the timing of childbirths. Milligan (2005) argues that the ANC impact was permanent rather than transitory, because the difference in the average number of childbirths between Quebec and the rest of Canada rose between 1991 and 1996. However, the ANC was enacted in 1988, and it is not likely that the transitory impact would be completed in eight years. Therefore, we directly compare the completed fertility levels of Quebec and the rest of Canada from 1934 to 1962 birth cohorts. ${ }^{11}$ We first test if the ANC impact varies by age group using household level Census data (see Table 3). We find strong support for age-specific responses to the ANC and the need to generate age-specific measure of ANC impact. Then we use completed fertility

11. We selected the 1962 birth cohort as the upper limit because completed fertility levels of 1963 and younger cohorts were not actual results but projections. 
Kim: Lifetime impact of cash transfer on fertility

level data to estimate the permanent impact of fertility (see Figure 4 and Table 4). Results indicate that there is little ANC impact on completed fertility.

Table 3 presents the regression results of equation (1). It reports the ANC impact coefficient of three subsamples by age group and the ANC coefficient of a pooled sample. We test if the birth probability of different age groups is differently affected by the ANC. From Table 3, the ANC im-

Table 3. Regression results by female age groups.

\begin{tabular}{|c|c|c|c|c|c|}
\hline \multirow{2}{*}{ Independent variables } & \multicolumn{5}{|c|}{ Age group } \\
\hline & & -24 & $25-34$ & 35 and over & Pooled \\
\hline $\begin{array}{l}\text { 15-24 × Quebec } \times 1996 \\
\text { dummy }\end{array}$ & $0.039 * *$ & $(0.016)$ & - & - & $* *(0.011)$ \\
\hline $\begin{array}{l}25-34 \times \text { Quebec } \times 1996 \\
\text { dummy }\end{array}$ & & - & $0.050^{* * *}(0.007)$ & - & $0.042 * * *(0.005)$ \\
\hline $\begin{array}{l}\text { 35+ } \times \text { Quebec } \times 1996 \\
\text { dummy }\end{array}$ & & - & - & $0.008 * * *(0.002)$ & $0.011 * * *(0.003)$ \\
\hline $15-24 \times$ Quebec & & - & - & - & $-0.113 * * *(0.008)$ \\
\hline $25-34 \times$ Quebec & & - & - & - & -0.004 \\
\hline $15-24 \times 1996$ dummy & & - & - & - & $-0.092 * * *(0.006)$ \\
\hline $25-34 \times 1996$ dummy & & - & - & - & $-0.028 * * *(0.003)$ \\
\hline Female age $15-24$ & & - & - & - & $0.284 * * *(0.004)$ \\
\hline Female age $25-34$ & & - & - & - & $0.315 * * *(0.002)$ \\
\hline 1996 dummy & -0.005 & $(0.011)$ & $-0.015 * * *(0.005)$ & $(0.001)$ & $0.007 * * *(0.002)$ \\
\hline Quebec & $-0.038 * *$ & $(0.017)$ & $-0.0004 \quad(0.008)$ & $0.013 * * *(0.002)$ & $0.013 * * *(0.003)$ \\
\hline One Older Child & $0.120 * * *$ & $*(0.018)$ & $0.104 * * *(0.004)$ & $0.025 * * *(0.001)$ & $0.047 * * *(0.001)$ \\
\hline Two or More Older Child & $0.121^{* *}$ & $(0.048)$ & $-0.267 * * *(0.005)$ & $-0.069 * * *(0.001)$ & $-0.094 * * *(0.001)$ \\
\hline Female immigrant & $0.097 * * *$ & $*(0.017)$ & $0.043 * * *(0.007)$ & $-0.004 * * \quad(0.002)$ & $0.006 * * *(0.002)$ \\
\hline Female Francophone & $0.120^{* * *}$ & $*(0.022)$ & $(0.010)$ & $-0.034 * * *(0.003)$ & $-0.027 * * *(0.003)$ \\
\hline Female Anglophone & $0.125^{* * *}$ & $*(0.017)$ & $(0.007)$ & $-0.014 * * *(0.002)$ & -0.004 \\
\hline Female high school & $-0.087 * * *$ & $*(0.010)$ & $0.014 * * \quad(0.005)$ & $0.005 * * *(0.001)$ & $0.008 * * *(0.002)$ \\
\hline Female post-high school & $-0.180 * * *$ & $*(0.009)$ & $-0.009 * \quad(0.006)$ & $0.022 * * *(0.001)$ & $0.008 * * *(0.002)$ \\
\hline Female university degree & $-0.285 * * *$ & $*(0.014)$ & $-0.080 * * *(0.006)$ & $0.062 * * *(0.002)$ & $0.014 * * *(0.002)$ \\
\hline Male age $25-34$ & $0.107 * * *$ & $*(0.008)$ & $0.152 * * *(0.009)$ & $0.348 * * *(0.004)$ & $0.160 * * *(0.003)$ \\
\hline Male age $35-44$ & $0.103^{* * *}$ & $*(0.021)$ & $0.122^{* * *}(0.009)$ & $0.175^{* * *}(0.003)$ & $0.123 * * *(0.003)$ \\
\hline Male age $45+$ & $-0.083^{*}$ & $(0.046)$ & $-0.076 * * *(0.007)$ & $-0.050 * * *(0.003)$ & $-0.111 * * *(0.003)$ \\
\hline Male immigrant & $-0.068^{* * *}$ & $*(0.016)$ & $0.013^{*} \quad(0.007)$ & $0.005 * * *(0.002)$ & $0.010 * * *(0.002)$ \\
\hline Male Francophone & $-0.324 * * *$ & $*(0.018)$ & $-0.084 * * *(0.009)$ & $-0.015 * * *(0.003)$ & $-0.030 * * *(0.003)$ \\
\hline Male Anglophone & $-0.289 * * *$ & $*(0.013)$ & $-0.076 * * *(0.007)$ & $-0.011 * * *(0.002)$ & $-0.029 * * *(0.002)$ \\
\hline Male high school & $-0.062 * * *$ & $*(0.010)$ & $0.004 * * *(0.005)$ & $0.0001 \quad(0.002)$ & 0.001 \\
\hline -high school & $-0.084 * * *$ & $*(0.009)$ & $0.018 * * *(0.005)$ & $0.011 * * *(0.001)$ & $0.011 * * *(0.002)$ \\
\hline Male university degree & $-0.131 * * *$ & $*(0.014)$ & $0.024 * * *(0.006)$ & $0.043 * * *(0.002)$ & $0.041 * * *(0.002)$ \\
\hline Married & $0.118^{* * *}$ & $*(0.027)$ & $0.035^{* * *}(0.011)$ & $0.012 * * *(0.004)$ & $0.026^{* * *}(0.004)$ \\
\hline Lives in $\mathrm{c}$ & $-0.064 * * *$ & $*(0.007)$ & $-0.044 * * *(0.004)$ & $0.012 * * *(0.001)$ & $-0.006 * * *(0.001)$ \\
\hline me $(C \$ 10000)$ & $-0.332 * * *$ & $*(0.018)$ & $-0.091 * * *(0.006)$ & $-0.006 * * *(0.001)$ & $-0.011 * * *(0.002)$ \\
\hline Provincial GDP growth & $0.014 * *$ & $(0.007)$ & $0.021 * * *(0.003)$ & $0.005 * * *(0.001)$ & $0.009 * * *(0.001)$ \\
\hline Provincial migration rate & $-0.045 * * *$ & $*(0.010)$ & $-0.047 * * *(0.005)$ & $(0.002)$ & $-0.015 * * *(0.002)$ \\
\hline $\begin{array}{l}\text { Provincial education } \\
\text { spending (C\$1000) }\end{array}$ & 0.001 & $(0.007)$ & $0.023 * * *(0.004)$ & $-0.110^{* * *}(0.001)$ & $0.013 * * *(0.001)$ \\
\hline Observations & & ,791 & 85,245 & 268,968 & 371,004 \\
\hline Adjusted $\mathrm{R}^{2}$ & & 194 & 0.077 & 0.181 & 0.333 \\
\hline
\end{tabular}

Dependent Variable: Had at least one child during the 5-year Census window.

Notes: This analysis is identical to the model specified in equation (1). The age cohort variables and important dummy variables are reported: '15-24 $\times$ Quebec $\times 1996$ dummy' indicates the dummy variable for households with female age 15-24 in the presence of the ANC, '25-34 × Quebec $\times 1996$ dummy' indicates the dummy variable for households with female age 25-34 in the presence of the ANC and '35+ $\times$ Quebec $\times 1996$ dummy' indicates the dummy variable for households with female age over 35 in the presence of the ANC. Standard errors are reported in parenthesis.

$* * *$ indicates significance at $1 \%$ level, $* *$ indicates significance at $5 \%$ level and $*$ indicates significance at $10 \%$ level. 
pact varies by age group. The birth subsidy impact on fertility is significant and positive for all age cohorts; however, it decreases by age, and the impact is only 0.8 per cent for the oldest cohort. In the pooled regression, the ANC impact on the youngest cohort is 6.6 per cent, and it is 4.2 per cent for the second-youngest cohort. The impact is 1.1 per cent for women older than 35 , and drastically diminishes for the oldest cohort, as the 35-plus age group passes the prime fertile years. ANC impact that varies by age group provides strong evidence that we need age-specific measures of ANC impact on fertility, to correctly define exposure to the ANC by birth cohort.

The completed fertility level of Quebec is consistently below the completed fertility level of the rest of Canada. The former slowly and consistently declines, from 3.02 in the 1934 birth cohort to 1.63 in the 1962 birth cohort. The latter also consistently declines, from 3.20 in the 1934 birth cohort to 1.87 in the 1962 birth cohort. Completed fertility levels for both Quebec and rest of Canada seem to move concurrently with each other, and age-adjusted exposure to ANC does not seem to affect the pattern of Quebecois completed fertility level differently from the completed fertility level of the rest of Canada.

Linear regression results from equation (2) are reported in Table 4. The models in panel (A) take the completed fertility level of Quebec as the dependent variable, and age-adjusted exposure to the ANC, completed fertility level of the rest of Canada, and linear and squared cohort-year variables as the independent variables. Age-adjusted exposure to the ANC is statistically insignificant for all models. We include the completed fertility level of the rest of Canada as an independent variable and the control for overall trend in Canadian completed fertility level — which may be incidentally correlated with ANC impact. As seen in Figure 4, the analysis summarized in panel (A) indicates that ANC does not have significant correlation with completed fertility level of Quebec.

We then tested whether the model was robust to the measure of ANC impact. Instead of using age-adjusted exposure to ANC as a proxy for ANC impact, we tried the number of childbearing years each cohort spent while the ANC was implemented. Childbearing age used is 15-44, as total fertility rate for a given year was measured as the total number of children that would be borne by a typical woman in a country if she is to speed through age 15 to 44 during the year. Panel (B) in Table 4 shows that the use of alternative measure as ANC impact has little impact on the result. In all three models, completed fertility level of Quebec is the dependent variable, and they progressively take number of childbearing years spent under ANC, completed fertility for the rest of Canada, cohort birth year, and its quadratic term as independent variables. As in panel (A), ANC impact does not have a significant impact on completed fertility. It is only significant in model (A), but as we introduce cohort birth year as the time trend, the significance disappears. Therefore, it seems that the correlation is robust to the use of ANC impact measure.

We estimate equation (3), taking completed fertility levels for both Quebec and the rest of Canada as dependent variables. The model takes age-adjusted exposure to ANC, cohort birth year, its quadratic term, and the Quebec indicator variable as independent variables. Age-adjusted exposure to ANC was assumed to be zero for the rest of Canada, regardless of cohort birth year. Panel (C) in Table 4 presents the estimation result of equation (3). The results indicate that age-adjusted exposure to ANC is significant in model (2) only. However, model (2) implicitly assumes that Quebec and the rest of Canada have identical time trend. We introduce Quebec specific time trend dummy variable in model (3), the interaction terms between Quebec dummy variable with linear and quadratic cohort year variables and controlling for Quebec-specific time trend, the significance disappears. Thus, panel (C) shows that age-adjusted exposure to ANC does not have a statistically significant impact on fertility level of Quebec. 
Kim: Lifetime impact of cash transfer on fertility

Table 4. Age-adjusted ANC exposure impact on completed fertility.

\begin{tabular}{|c|c|c|c|}
\hline & (1) & $(2)$ & (3) \\
\hline \multicolumn{4}{|c|}{ Panel A: Dependent variable - completed fertility of Quebec } \\
\hline $\begin{array}{l}\text { Age-adjusted exposure to ANC } \\
\text { (per } 1,000 \text { women) }\end{array}$ & $\begin{array}{l}0.00002 \\
(0.00004)\end{array}$ & $\begin{array}{l}0.00076 * * * \\
(0.00016)\end{array}$ & $\begin{array}{l}-0.00008 \\
(0.00010)\end{array}$ \\
\hline Completed fertility of rest of Canada & $\begin{array}{l}0.99133 * * * \\
(0.02385)\end{array}$ & $\begin{array}{l}0.40181 * * * \\
(0.12744)\end{array}$ & $\begin{array}{l}0.38039 * * * \\
(0.05068)\end{array}$ \\
\hline Cohort birth year & & $\begin{array}{l}-0.05028 * * * \\
(0.01076)\end{array}$ & $\begin{array}{l}-7.15645^{* * * *} \\
(0.61326)\end{array}$ \\
\hline Cohort birth year squared & & & $\begin{array}{l}0.00183 * * * \\
(0.00016)\end{array}$ \\
\hline Observations & 29 & 29 & 29 \\
\hline Adjusted $\mathrm{R}^{2}$ & 0.991 & 0.995 & 0.999 \\
\hline \multicolumn{4}{|c|}{ Panel B: Dependent variable - completed fertility of Quebec } \\
\hline $\begin{array}{l}\text { Number of childbearing years (15-44) spent } \\
\text { under ANC }\end{array}$ & $\begin{array}{l}0.00326 \\
(0.00425)\end{array}$ & $\begin{array}{l}0.00719 \\
(0.00590)\end{array}$ & $\begin{array}{l}0.00058 \\
(0.00183)\end{array}$ \\
\hline Completed fertility of rest of Canada & $\begin{array}{l}1.01124 * * * \\
(0.04081)\end{array}$ & $\begin{array}{l}0.98123 * * * \\
(0.05142)\end{array}$ & $\begin{array}{l}0.35848 * * * \\
(0.04218)\end{array}$ \\
\hline Cohort birth year & & $\begin{array}{l}-0.00374 \\
(0.00389)\end{array}$ & $\begin{array}{l}-6.74992 * * * \\
(0.42504)\end{array}$ \\
\hline Cohort birth year squared & & & $\begin{array}{l}0.00172 * * * \\
(0.00011)\end{array}$ \\
\hline Observations & 29 & 29 & 29 \\
\hline Adjusted $\mathrm{R}^{2}$ & 0.991 & 0.991 & 0.999 \\
\hline
\end{tabular}

Panel C: Dependent variable - completed fertility level of Quebec and the rest of Canada (pooled sample)

Age-adjusted exposure to ANC $\quad-0.09844 \quad-0.32126^{* * *} \quad 0.00013$

Quebec dummy

Time trend dummy

Quebec-specific time trend dummy variables

Adjusted $\mathrm{R}^{2}$

\begin{tabular}{rrr}
$(0.12362)$ & $(0.01570)$ & $(0.00010)$ \\
Yes & Yes & Yes \\
No & Yes & Yes \\
No & No & Yes \\
\hline 58 & 58 & 58 \\
0.258 & 0.990 & 0.990 \\
\hline
\end{tabular}

Note: The analysis in panel (A) is identical to the model specified in equation (2). For the analysis presented in panel (B), we replaced the measure of ANC impact with the number of years spent under ANC during birth years of 15-49. The analysis in panel (C) is identical to the model specified in equation (3). The time trend dummy variables in panel (C) are the cohort birth year and its quadratic term. Quebec specific time trend dummy variables are the interaction term between Quebec dummy variable and cohort birth year and its quadratic term. Standard errors are reported in parenthesis. *** indicates significance at $1 \%$ level, $* *$ indicates significance at $5 \%$ level and * indicates significance at $10 \%$ level.

In theory, costly cash transfer schemes that reduce childrearing costs may have a positive impact on fertility (Becker 1960). However, whether the subsidy amount is substantial enough to have a permanent impact on fertility is an empirical question. It depends on the number of households at the margin whose lifetime fertility is affected by the cash transfer amount. Assuming that the utility of a child is diminishing with the number of children and that the cost of childrearing is constant over the parity of births, cash subsidies may not be enough to increase the total number of lifetime births. Instead, for households with borrowing constraints, cash subsidies may only be enough for 
them to have the child who they are already saving up for. Therefore, whether the subsidy is substantial enough to encourage households to increase the total number of children is an empirical question, as children are discrete and expensive.

The mechanism is formally illustrated in a simple two-period fertility decision model, with a liquidity constraint, in Parent and Wang (2007). Assuming the cost of a child is identical over the period, and also assuming that utility from the first child exceeds the cost of a child, households bound by a liquidity constraint in the first period would be able to have a child in the first period. However, whether the household has another child in the second period would depend on if the size of child benefit is sufficient to make the utility from the second child greater than the cost of a child. If the child benefit is insufficient to increase lifetime fertility, it merely has a temporal effect on the timing of births. Using difference-in-difference analysis on household-level Census data, they also show that the impact of reformed the Family Allowance program of Canada in the mid-1970s, as indicated in Zhang et al. (1994), is actually temporal, emphasizing that the lack of permanent effect is an empirical issue. This means that the ANC may not be substantial enough to have a permanent impact on fertility, either.

Analysis of the age-adjusted exposure to ANC and completed lifetime fertility level of Quebec shows that the ANC impact is not permanent. The ANC cash transfer amount did not affect a significant number of households at the margin such that their lifetime fertility was affected by the subsidy amount. The evidence implies that a significant number of households who are not at the margin did shift the timing of births in response to the ANC.

\section{Concluding remarks}

The Allowance for Newborn Children (ANC) from Quebec was a fiscal incentive scheme to stimulate birth; it had a positive and significant impact on fertility. However, the ANC impact may have been due mainly to the shift in the timing of childbirth, and not to an increase in lifetime fertility level. The permanent impact of the ANC is more accurately tested by using completed fertility level of the female birth cohort. It may be more accurate to estimate the permanent impact of pro-natal cash transfer by analyzing the impact on completed fertility level rather than on a cross-sectional dataset, as was previously done, for the transfer may have prompted a statistically significant temporal shift in birth timing as well. Although there is a mechanical link between fertility level and childrearing cost, the subsidy amount must be substantial enough to permanently influence enough households that are willing to increase their lifetime fertility, because children are innately discrete and expensive. The ANC subsidy amount relative to the total childrearing cost seems insufficient to increase the total lifetime fertility of affected households, and thus the cash transfer policy had little impact on the lifetime fertility increase.

Childrearing is costly; hence, cash transfer schemes to reduce childrearing costs are costly, as well. Using the method highlighted in Phipps (1998), the ANC transfer amount accounted for 1.3 per cent, 3.2 per cent, and 30.1 per cent of the direct cost of children (Duclos et al. 2001). The cost of children also has indirect economic costs. It affects savings, consumption, and labour supply decisions of a household (Browning 1992); hence, the ANC transfer amount may be smaller than the estimate if indirect economic costs are accounted for. This paper shows that cash transfers of such a magnitude are not substantial enough to increase completed fertility levels, but they may only shift the timing of births in the affected population. 
Kim: Lifetime impact of cash transfer on fertility

All OECD countries except for Turkey and Mexico have below-replacement level fertility (OECD 2005), and all OECD countries implement pro-natal policies in one form or another (Sleebos 2003). The cash transfer scheme is a popular policy choice in many OECD countries spanning different continents, including Australia, Belgium, France, Germany, New Zealand, South Korea, and Sweden, but the long-term impacts of such cash transfers have not been fully tested. This may be due to the indisputable benefits of ease of monitoring, ease of implementation, and political decision-making. However, as they become available, if future studies with more completed fertility level data also reveal that the long-term impacts of cash transfers are limited, immigration may be an alternative solution for policymakers who are genuinely concerned about declining national income and productivity, as well as rising burdens on government budgets due to the current fertility transition in developed countries.

\section{Acknowledgments}

We are indebted to Gary Becker, Patrick Heuveline, and John List for their helpful comments and interest in this project. We thank Jungmin Lee, Sok Chul Hong, Sung Man Moon and participants at a number of seminars for their valuable inputs. This work was supported by a Sogang University Research Grant.

\section{References}

Baril, R., P. Lefebvre, and P. Merrigan. 2000. Quebec family policy: Impact and options. The Institute for Research on Public Policy (IRPP) 6(1):4-31.

Becker, G.S. 1960. An Economic Analysis of Fertility: Demographic and Economic Change in Developed Countries. NBER Series 11. Princeton, NJ: Princeton University Press, pp. 209-231.

Browning, M. 1992. Children and household economic behavior. Journal of Economic Literature 30(3):1434-1475.

Buttner, T., and W. Lutz. 1990. Estimating fertility responses to policy measures in the German Democratic Republic. Population and Development Review 16(3):539-555.

Cohen, A., R. Dehejia, and D. Romanov. 2007. Do Financial Incentives Affect Fertility? NBER Working Paper 13700.

Duclos, E., P. Lefebvre, and P. Merrigan. 2001. A Natural Experiment on the Economics of Storks: Evidence on the Impact of Differential Family Policy on Fertility Rates in Canada. CREFE Working Paper No. 136.

Hoem, J.M. 1990. Social policy and recent fertility change in Sweden. Population and Development Review 16(4):735-748.

Milligan, K. 2005. Subsidizing the stork: New evidence on tax incentives and fertility. Review of Economics and Statistics 87(3):539-555.

OECD. 2005. Trends and determinants of fertility rates in OECD countries: The role of policies. OECD Social, Employment, and Migration Working Papers.

Parent, D., and L. Wang. 2007. Tax incentives and fertility in Canada: Quantum vs tempo effects. Canadian Journal of Economics 40(2):371-400. 
Phipps, S. 1998. What is the income 'cost of a child'? Exact equivalence scales for Canadian two-parent families. Review of Economics and Statistics 80(1):157-164.

Salanie, B., and G. Laroque. 2008. Does Fertility Respond to Financial Incentives? IZA Discussion Paper No. 3575.

Sleebos, J.E. 2003. Low Fertility Rates in OECD Countries: Facts and Policy Responses. OECD Social, Employment and Migration Working Papers.

Zhang, J., J. Quan, and P. Van Meerbergen.1994. The effect of tax-transfer policies on fertility in Canada, 1921-88. Journal of Human Resources 29(1):181-201. 